\title{
PANEL DINDING GEOPOLIMER DENGAN PERKUATAN WIREMESH
}

\author{
Andini Pratiwi Putri ${ }^{1}$, Iman Satyarno ${ }^{2}$, Ashar Saputra ${ }^{3}$ \\ 1,2,3 Departemen Teknik Sipil dan Lingkungan, FT, Universitas Gadjah Mada \\ Email: andini.pratiwi.p@mail.ugm.ac.id
}

\begin{abstract}
ABSTRAK
Pengembangan fly ash berbasis geopolimer sangat cocok untuk memperluas aplikasi pracetak khususnya panel dinding pada lingkungan asam sulfat. Panel berbahan abu terbang ini dapat dijadikan pertimbangan karena memiliki keunggulan diantaranya kekerasan tinggi, ramah lingkungan, tidak menghasilkan gas karbon (CO2), tahan pada temperatur panas antara $600-800^{\circ} \mathrm{C}$, tahan lingkungan asam, dan tidak memerlukan perawatan panas. Untuk pembuatan struktur panel pracetak menggunakan bahan pengisi berupa mortar berbahan geopolimer dengan komposisi $\mathrm{NaOH} 14 \mathrm{M}$, rasio $\mathrm{NaOH} / \mathrm{Na2SiO3}$ sebesar 1 :2, rasio alkaline : fly ash sebesar 35\%, dan menggunakan variasi wiremesh sebagai perkuatan, dengan ukuran benda uji panel $800 \times 400 \times 40 \mathrm{~mm}$. Hasil yang didapat kuat tekan umur 1 hari sebesar 11.27 MPa umur 28 hari 60,84 MPa, dengan nilai modulus 28 hari sebesar $13808 \mathrm{MPa}$. Pengujian kuat tarik 1 hari sebesar $1.02 \mathrm{MPa}$ dan 28 hari sebesar 2,95 MPa Pengujian kuat lentur didapatkan 3,52 MPa tanpa perkuatan dan 4,52 dengan perkuatan.
\end{abstract}

Kata kunci: Geopolymer, panel, wiremesh

\begin{abstract}
Geopolymer-based fly ash development is perfect for expanding precast applications especially wall panels in sulfuric acid environments. Panels made of fly ash can be considered because it has the advantage of high hardness, environmentally friendly, does not produce carbon gas (CO2), resistant to heat temperature between $600-800{ }^{\circ} \mathrm{C}$, resistant to acidic environment, and not require hot maintenance. To create the structure of precast panels using mortar filling material with geopolymer with composition $\mathrm{NaOH} 14 \mathrm{M}$, ratio of $\mathrm{NaOH} / \mathrm{Na2SiO} 3$ is 1:2, ratio alkaline ratio: fly ash $35 \%$, and use wiremesh variation, size of panel $800 \times 400 \times 40 \mathrm{~mm}$. Results obtained compressive strength of 1 day 11.27 MPa, age 28 Days 60.84 MPa, modulus elasticity 28-day 13808 MPa. Result tensile strength 1-day 1.02 MPa and 28 days $2.95 \mathrm{MPa}$, frexural strength panel $3.52 \mathrm{MPa}$ without wiremesh and 4.52 with wiremesh.
\end{abstract}

Keywords: Geopolymer, panels, wiremesh

\section{PENDAHULUAN}

Beton merupakan material yang paling banyak digunakan sebagai bahan konstruksi karena memiliki karakteristik material yang handal dalam segi kekuatan, dan kemudahan dalam pekerjaannya. Akan tetapi untuk beton normal memiliki banyak kekurangan diantaranya durabilitas yang buruk pada lingkungan agresif asam sulfat, proses produksinya melepaskan gas $\mathrm{CO}_{2} \mathrm{ke}$ atmosfir sehingga dapat menimbulkan

INERSIA, Vol. XVI No. 1, Mei 2020 pemanasan global. Seiring perkembangan ilmu pengetahuan, teknologi polimerisasi mulai dikembangkan dan memberikan inovasi terbaru di dunia industri beton sebagai bahan alternativ pengganti beton. Penggunaan beton berbahan geopolimer juga dapat mengurangi dampak pemanasan global yang terjadi akibat pelepasan gas $\mathrm{CO}_{2}$. 
Beton geopolimer merupakan material sintesa bahan-alam anorganik melalui proses polimerisasi dimana bahan utama dalam pembuatan geopolimer adalah unsur silika dan alumunium yang direaksikan secara kimia dengan larutan alkali sehingga menghasilkan pasta geopolimer. Pasta geopolimer ini ketika digabungkan dengan agregat akan menghasilkan beton geopolimer (Hardjito dkk, 2002).

Menurut Duxson dkk (2007), penggunaan beton geopolimer menyebabkan durabilitas beton akan terjaga sehingga memiliki durabilitas kerja jangka panjang, selain itu penggunaan teknologi ini bisa mengurangi $\mathrm{CO}_{2}$ sekitar $80 \%$.

Berdasarkan uraian yang telah disampaikan di atas diperlukan adanya kajian lebih lanjut terhadap aplikasi pemanfaatan menjadi panel beton yang selain memiliki durabilitas yang baik, memiliki kekuatan yang tinggi dan juga ramah lingkungan.

Panel dinding berbahan dasar abu terbang merupakan terobosan terbaru dalam teknologi konstruksi. Hardjito dkk (2004) menyebutkan keunggulan menggunakan geopolimer diantaranya kekerasan tinggi, ramah lingkungan, tidak menghasilkan gas karbon $\left(\mathrm{CO}_{2}\right)$, tahan pada temperatur panas antara $600-800^{\circ} \mathrm{C}$, tahan terhadap lingkungan asam, dan tidak memerlukan perawatan panas sehingga dapat mudah digunakan bagi masyarakat luas.

Rajendran dan Nagan (2015) melakukan penelitian terkait pangaruh kekuatan tekan geopolimer terhadap variasi $\mathrm{NaOH}$ yang digunakan. Bahan penelitian menggunakan variasi $\mathrm{NaOH} 8 \mathrm{M}, 10 \mathrm{M}, 12 \mathrm{M}, 14 \mathrm{M}$, rasio perbandingan $\mathrm{Na}_{2} \mathrm{SiO}_{3} / \mathrm{NaOH}$ dipertahankan 1:1. Benda uji menggunakan kubus ukuran $50 \times 50 \times 50 \mathrm{~mm}$ dengan umur pengujian 28 hari. Hasil didapatkan kuat tekan tertinggi dengan penggunaan $\mathrm{NaOH}$ $14 \mathrm{M}$ sebesar $60,02 \mathrm{MPa}$.

Cornelis, (2018) menjelaskan dalam penelitiannya menggunakan fly ash tipe C yang mengandung kalsium oksida yang tinggi sekitar $8-15 \%$ berat. Kalsium oksida ini berperan meningkatkan pengaturan waktu menjadi cepat. Pengujian kuat tekan dilakukan dengan menggunakan benda uji kubus ukuran $50 \times 50 \times 50 \mathrm{~mm}$ dengan konsentrasi $10 \mathrm{M} \mathrm{NaOH}$, rasio natrium silikat : natrium hidroksida yaitu 2 , rasio alkali:fly ash sebesar $35 \%$, rasio volume pasta : volume rongga agregat halus 1,5 dan alkali untuk rasio cementitious (A) 0,35. Hasil penelitian menyebutkan nilai kuat tekan pada 28-hari yang dihasilkan sebesar $53,7 \mathrm{MPa}$.

Hardjito, dkk (2004) melakukan kajian tentang pengaruh ketahanan beton geopolymer terhadap sulfat. Kajian ini menggunakan parameter $\mathrm{NaOH} 8 \mathrm{M}$, dan $14 \mathrm{M}$, rasio massa perbandingan $\mathrm{Na}_{2} \mathrm{SiO}_{3}$ : $\mathrm{NaOH}$ 0,4 dan 2,5, dan rasio massa alkalin dengan fly ash dijaga konstan 0,35 . Untuk mengevaluasi ketahanan geopolymer terhadap serangan sulfat serangkaian tes berupa perendaman benda uji dalam sodium sulfat $5 \%$ untuk periode waktu tertentu. Hasil tes dilakukan setelah 12 minggu paparan, tidak ada perubahan yang signifikan terhadap kuat tekan, massa dan panjang benda uji.

Sreevidya dkk (2014) melakukan penelitian tentang analisa kekuatan lentur dengan bahan ferrocement menggunakan ukuran $760 \times 150 \times 30 \mathrm{~mm}$. Wiremesh yang digunakan woven mesh, welded mesh dan expanded mesh dengan variasi masing-masing mesh berjumlah satu layer, dua layer. Pengujian dilakukan setelah umur benda uji 28 hari. Hasil penelitian menunjukkan woven mesh mengalami retak saat beban mencapai $1 \mathrm{kN}$ untuk lapisan ganda dan untuk lapisan tunggal terjadi pada $0,8 \mathrm{kN}$. Untuk expanded mesh retak awal terjadi pada $1 \mathrm{kN}$ untuk lapisan ganda dan untuk lapisan tunggal terjadi di $0,8 \mathrm{kN}$. Untuk welded mesh retak awal terjadi pada $1,4 \mathrm{kN}$ double lapisan dan untuk lapisan tunggal terjadi di $1 \mathrm{kN}$. Kajian ini dapat dianggap sebagai welded mesh dapat memberikan peningkatan yang signifikan dalam perilaku lentur dibandingkan menggunakan expanded mesh dan woven mesh.

Shofi dkk (2016) melakukan penelitian tentang analisa kekuatan lentur dengan bahan ferrocement. Wiremesh yang 
digunakan yaitu woven mesh, welded mesh dan expanded mesh. Peneliti menyebutkan penggunaan expanded mesh mengalami retak untuk lapisan ganda terjadi saat 2,2 kN dan untuk lapisan tunggal terjadi saat 1,8 $\mathrm{kN}$. Untuk woven mesh retak awal untuk lapisan ganda terjadi pada $2 \mathrm{kN}$ dan untuk lapisan tunggal terjadi pada 1,8 kN. Untuk welded mesh retak awal double lapisan terjadi pada $2,8 \mathrm{kN}$ dan untuk lapisan tunggal terjadi pada 2,2 kN. Kajian ini dapat dianggap sebagai welded mesh dapat memberikan peningkatan kekuatan yang signifikan dalam perilaku lentur dibandingkan menggunakan expanded mesh dan woven mesh.

Alkalin activator merupakan bahan kimia yang dibutuhkan untuk reaksi polimerisasi. Selama proses curing (pengerasan) ikatan tersebut akan membentuk jaringan polimer yang berikatan silang. Aktivator yang umum digunakan adalah larutan sodium silikat dan sodium hidroksida (Utomo, 2012)

Sodium hidroksida $(\mathrm{NaOH})$ digunakan sebagai media cairan bahan campuran untuk membuat material geopolimer, sodium hidroksida ini berfungsi mereaksikan unsur Si-Al membentuk ikatan ion yang kuat saat polimerisasi.

Sodium silikat $\left(\mathrm{Na}_{2} \mathrm{SiO}_{3}\right)$ juga digunakan sebagai bahan campuran untuk membuat material geopolimer, sodium silikat ini berfungsi mempercepat reaksi polimerisasi sehingga berpengaruh kepada kuat tekan yang dihasilkan beton. Bentuk dari sodium silikat dapat berupa cairan atau padatan

Air berfungsi untuk melarukan sodium hidroksida dan sodium silikat. Menurut Tjokrodimuljo (2012) air yang digunakan untuk campuran beton harus memenuhi standart persyaratan diantaranya harus bersih, tidak mengandug lumpur dan benda lainnya, tidak mengandung garam mineral dan senyawa sulfat.

Shah dan Kejin berpendapat fly ash terdiri dari ikatan (amorf) alumina-silikat dan ikatan kristal dimana apabila dicampur dengan alkali dapat mengaktifkan hidrasi dan membentuk ikatan polarisasi.
Menurut ASTM C618 dijelaskan spesifikasi pengelompokkan fly ash terdiri dari tiga jenis, yaitu:

a. Abu terbang kelas $\mathrm{N}$, dapat diperoleh dari tanah diatomice, shale, tuft, batu apung, dan abu vulkanik.

b. Abu terbang kelas $F$, dihasilkan dari pembakaran batu bara jenis antrasit pada suhu $1560^{\circ} \mathrm{C}$. Fly ash ini memiliki sifat pozzolan.

c. Abu terbang kelas $\mathrm{C}$, dari pembakaran batu bara. Fly ash ini memiliki sifat pozzolan dan juga memiliki beberapa sifat semen (kandungan Carbon > 10\%)

Agregat halus merupakan bahan mineral alami berupa butiran yang berfungsi sebagai bahan pengisi dalam campuran beton. Kekuatan suatu beton dipengaruhi oleh kualitas dari masing-masing agregat yang menempati $70 \%$ volume mortar atau beton. Agregat halus menurut ACI $5491 R$ 93 yaitu agregat yang telah memenuhi standart bersih bebas dari materi yang merusak, bebas dari lumpur dan tanah liat. Menurut Tjokrodimuljo (2012) beberapa syarat yang harus dimiliki oleh agregat halus, yaitu:

a. Pasir terdiri dari butir- butir tajam dan keras. Dengan indeks kekerasan $\leq 2,2$

b. Tidak mengandung lumpur lebih dari $5 \%$

c. Tidak mengandung bahan-bahan organik terlalu banyak yang dibuktikan dengan percobaan warna dari AbramsHarder dengan larutan $3 \% \mathrm{NaOH}$, yaitu warna endapan agregat halus tidak boleh gelap dari warna pembanding

d. Modulus halus butir antara 1,5 sampai 3,8 dengan variasi butir sesuai standar gradasi.

e. Untuk beton mutu keawetan tinggi, agregat halus harus tidak reaktif terhadap alkali.

f. Agregat halus dari laut/pantai boleh dipakai dengan petunjuk lembaga pemeriksaan bahan yang diakui.

Wiremesh adalah suatu bahan penulangan baja yang terbuat dari kawat baja yang dilas dan memiliki jarak antar kawat yang seragam yang digunakan dalam perkuatan dalam beton (Sari, 2011). 
Menurut ACI 549.1R-93 kawat anyam yang digunakan untuk perkuatan memiliki persyaratan bersih dan bebas dari debu, karat lepas, lapisan cat, minyak, atau zat serupa. Desain kekuatan kawat ayam didasarkan pada kekuatan luluh fy tetapi tidak boleh melebihi 100.000 psi (690 MPa). Tipe wiremesh dengan kabel berjarak dekat dengan bukaan heksagonal atau persegi adalah penguatan yang paling umum digunakan.

\section{METODE}

Kajian ini menggunakan metode studi eksperimental dengan percobaan langsung di laboratorium.

Peralatan Pembuatan Benda Uji

1. Timbangan kapasitas $150 \mathrm{~kg}$

2. Molen

3. Cetakan kubus

4. Cetakan catebone

5. Cetakan silinder diameter $150 \mathrm{~mm}$

6. Cetakan panel

\section{Peralatan Pengujian}

1. UTM (Universal Testing Machine)

2. CTM (Compression Testing Machine)

3. Flexural Strength

4. Mesin Uji Tarik

5. Dial Gauge

6. LVDT

7. Data Logger

\section{Benda Uji}

Adapun jenis dan kebutuhan benda uji dapat dilihat pada Tabel 1.

Tabel 1. Kebutuhan Pembuatan Benda Uji

\begin{tabular}{ccccc}
\hline $\begin{array}{c}\text { Fly ash } \\
(\mathrm{kg})\end{array}$ & $\begin{array}{c}\text { Agregat } \\
\text { halus } \\
(\mathrm{kg})\end{array}$ & $\begin{array}{c}\mathrm{Na}_{2} \mathrm{SiO}_{3} \\
(\mathrm{~kg})\end{array}$ & & \multicolumn{2}{c}{$\mathrm{NaOH}(\mathrm{kg})$} \\
\cline { 4 - 5 } & & & Pellet & Aquades \\
\hline 1138,48 & 927,75 & 266,44 & 62,17 & 71,05 \\
\hline
\end{tabular}

Desain Panel

Pada panel dinding yang akan diuji menggunakan dua variasi yaitu variasi 1 panel dinding tanpa menggunakan perkuatan wiremesh dan variasi 2 yaitu panel dinding menggunakan perkuatan wiremesh. Untuk ukuran benda uji panel yang digunakan yaitu $800 \times 400 \times 40 \mathrm{~mm}$.

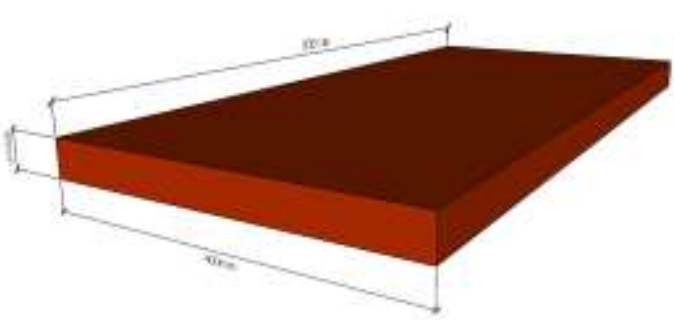

Gambar 1. Desain panel dinding variasi 1

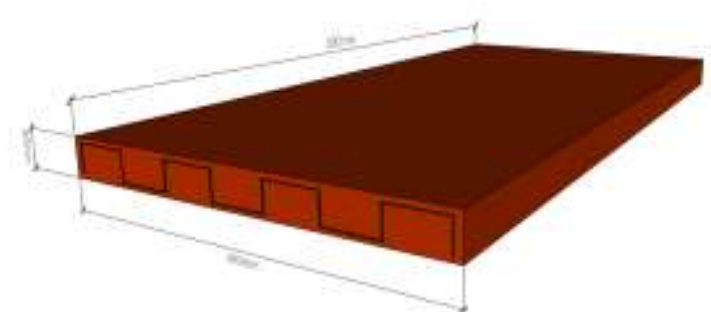

Gambar 2. Desain panel dinding variasi 2

Pengujian Material

Langkah pertama yang dilakukan adalah melakukan pengujian material penyusun geopolimer untuk mengetahui komposisi yang terkandung di dalamnya. Pengujian ini meliputi pengujian pada fly ash, agregat halus, air, $\mathrm{NaOH}, \mathrm{Na}_{2} \mathrm{SiO}_{3}$

Perhitungan Analisis Campuran

Perencanaan campuran menggunakan komposisi $\mathrm{NaOH} 14 \mathrm{M}$, perbandingan fly ash dan alkaline sebesar 1:0,35, perbandingan $\mathrm{NaOH}: \mathrm{Na}_{2} \mathrm{SiO}_{3} \quad 1: 2$, Perbandingan agregat halus dan rongga pasta sebesar $1: 1,5$.

Berdasarkan perhitungan menggunakan volume absolut didapatkan hasil perancangan campuran geopolimer yang dapat dilihat pada Tabel 2 .

Tabel 2. Kebutuhan bahan per $\mathrm{m}^{3}$

\begin{tabular}{cccc}
\hline Pengujian & Benda Uji & $\begin{array}{c}\text { Variasi } \\
\text { kawat }\end{array}$ & $\begin{array}{c}\text { Umur } \\
\text { (hari) }\end{array}$ \\
\hline $\begin{array}{c}\text { Kuat Tekan } \\
\text { Mortar }\end{array}$ & $\begin{array}{c}\text { Kubus } \\
50 \times 50 \mathrm{~mm}\end{array}$ & 0 & 1 dan 28 \\
\hline Kuat Tarik & Catbone & 0 & 1 dan 28 \\
\hline Modulus & $\begin{array}{c}\text { Silinder } \\
150 / 300 \mathrm{~mm}\end{array}$ & 0 & 1 dan 28 \\
Elastisitas & $\begin{array}{c}\text { Panel } \\
\text { Panel Lentur }\end{array}$ & 0 dan 1 & 28 \\
\hline $\begin{array}{c}800 \times 400 \times 40 m \\
\mathrm{~m}\end{array}$ & 0 dan 1 & 28 \\
\hline Kuat Geser & $\begin{array}{c}\text { Panel } \\
800 \times 400 \times 40 \\
\mathrm{~mm}\end{array}$ & & \\
\hline
\end{tabular}


Prosedur pencampuran mortar dilakukan dengan tahapan sebagai berikut:

1 Pembuatan larutan $\mathrm{NaOH} 14 \mathrm{M}$ dengan cara menimbang pellet $\mathrm{NaOH}$ sebesar 14 x 40 (berat molekul $\mathrm{NaOH}$ ) yaitu 560 gram, kemudian dimasukkan ke dalam $800 \mathrm{ml}$ air dan diaduk hingga semua pellet larut keseluruhan. Kemudian ditambahkan air hingga volume larutan mencapai $1000 \mathrm{ml}$.

2 Larutan $\mathrm{Na}(\mathrm{OH}) 14 \mathrm{M}$ dan $\mathrm{Na}_{2} \mathrm{SiO}_{3}$ disiapkan, selanjutnya dicampur dan diaduk hingga membentuk larutan alkali. Larutan ini didiamkan minimal 1 jam sebelum dilakukan pencampuran mortar.

3 Fly ash kemudian ditimbang sesuai kebutuhan kemudian dimasukkan ke dalam mixer dalam keadaan kering.

4 Larutan alkali dituang secara perlahan ke dalam mixer, dan diaduk lebih kurang 5 menit.

5 Agregat halus dimasukkan ke dalam mixer dan diaduk dalam kurun waktu 2 menit.

6 Putaran dihentikan dan mortar siap diuji pada flow table.

7 Bahan yang telah diaduk kemudian dimasukkan kedalam cetakan yang telah dioles dengan pelumas.

8 Benda uji diberi kode, kemudian diuji pada umur pengujian.

\section{Uji Flow Table Test}

Pengukuran workabilitas pada mortar dilakukan menggunakan meja getar atau flow table test sesuai ASTM C1437-07. Cara kerja tes ini dengan mengukur tingkat penyebaran campuran ketika menerima hentakan pada flow table selama 25 kali dalam 15 detik. Diameter dasar mortar yang telah memesar diukur empat tahap dilokasi yang berbeda dan dicatat.

\section{Kuat Tekan}

Kuat tekan adalah perbandingan dari besarnya beban per satuan luas. Pada pengujian ini didapatkan melalui tata cara pengujian memberikan beban tertentu pada benda uji sampai benda uji hancur. Secara matematis dinyatakan sebagai berikut:

dimana :

$$
f c^{\prime}=\frac{P}{A}
$$

fc' : Kuat tekan beton (MPa)
P : Beban maksimum (N)
A : Luas penampang $\left(\mathrm{mm}^{2}\right)$

\section{Kuat Tarik}

Pengujian ini bertujuan untuk mengetahui besar kuat tarik mortar dan luas tarik mortar tersebut. Pengujian ini mengacu pada standart ASTM C307-03. Uji kuat tarik mortar dilakukan dengan membuat benda uji seperti angka delapan dengan cetakan bernama catbone. Setelah itu benda uji dipasang pada mesin uji tarik dan dilaksanakan pengujian hingga benda uji patah atau retak.

$$
S=\frac{P}{A}
$$

dimana :

$S \quad$ : Tegangan tarik mortar pada leher benda uji (MPa)

$\mathrm{P} \quad$ : Beban maksimum (N)

A : Luas penampang pada leher benda uji $\left(\mathrm{mm}^{2}\right)$

\section{Modulus Elastisitas}

Modulus Elastisitas merupakan rasio dari tegangan normal tarik atau tekan terhadap regangan. Modulus elastisitas tergantung pada umur beton, sifat bahan yang membentuk, kecepatan pembebanan, jenis dan ukuran benda uji. Pengujian ini menggunakan silinder beton dengan ukuran diameter $150 \mathrm{~mm}$ dan tinggi $300 \mathrm{~mm}$. Untuk perhitungan modulus elastisitas digunakan standar perhitungan ASTM C469-02 dengan rumus:

dimana:

$$
E c=\frac{\sigma 2-\sigma 1}{\varepsilon 2-\varepsilon 1}
$$

Ec : Modulus elastisitas beton $\left(\mathrm{kg} / \mathrm{m}^{3}\right)$

o2 : Tegangan pada $40 \%$ tegangan runtuh $(\mathrm{kg})$

o1 : Tegangan pada saat nilai kurva $\varepsilon 1$ $(\mathrm{kg})$

ع2 : Nilai kurva regangan pada saat $\sigma 2$ $\left(\mathrm{m}^{3}\right)$

$\varepsilon 1 \quad$ : Regangan sebesar $0,00005\left(\mathrm{~m}^{3}\right)$

5. Kuat Lentur

Menurut Singer dan Pytel (1985) regangan lentur adalah tegangan yang disebabkan oleh momen lentur. Hubungan antara keduanya dapat dihitung mengikuti prosedur deformasi elastis dan hokum Hooke yang menetapkan sifat variasi 
tegangan, kemudian kondisi kesetimbangan membuat hubungan antara tegangan dan beban. Tegangan lentur maksimum dapat diperoleh dengan rumus :

$$
\mathrm{f}_{\text {maks }}=\frac{\text { Mmaks } . y}{I}
$$

Perhitungan momen didapatkan dari persamaan berikut :

$$
\text { Mmaks }=\frac{1}{8} q L^{2}+\frac{1}{6} P L
$$

dimana :

$$
\begin{array}{ll}
\mathrm{f}_{\text {maks }} & \begin{array}{l}
\text { : Tegangan lentur maksimum panel } \\
(\mathrm{MPa})
\end{array} \\
\mathrm{M}_{\text {maks }} & \begin{array}{l}
\text { : Momen lentur masksimum panel } \\
(\mathrm{MPa})
\end{array} \\
\mathrm{y} & \begin{array}{l}
: \text { Jarak serat terluar terhadap garis } \\
\text { netral }(\mathrm{mm})
\end{array} \\
\mathrm{I} & \begin{array}{l}
\text { : Momen inersia penampang }\left(\mathrm{mm}^{4}\right) \\
\mathrm{q}
\end{array} \\
\begin{array}{l}
\text { : Berat panel per meter panjang } \\
(\mathrm{kN} / \mathrm{m})
\end{array} \\
\mathrm{P} & : \text { Beban terpusat }(\mathrm{kN}) \\
\mathrm{L} & : \text { Panjang panel antar tumpuan }(\mathrm{mm})
\end{array}
$$

Rumus dengan persamaan (2), (3) digunakan sebagai pembanding tegangan lentur dinding beton saat elastis. Apabila digunakan untuk beton komposit harus dilakukan transformasi luasan teoritik antara bahan satu dengan lainnya. Persamaan dapat dihitung dengan rumus berikut:

$$
\mathrm{N}=\frac{E s}{E m}
$$

Luasan beton yang ditransformasikan:

$$
A=n \times \text { As }
$$

Momen Inersia yang mengalami transformasi:

dimana:

$$
\mathrm{I}=\mathrm{n} \times \mathrm{Is}
$$

Es : Modulus elastisitas kawat jala (MPa)

Em : Modulus elastisitas mortar (MPa)

A : Luasan beton yang ditransformasikan ke mortar $\left(\mathrm{mm}^{2}\right)$

As : Luasan kawat jala $\left(\mathrm{mm}^{2}\right)$

I : Momen inersia beton yang telah ditransformasikan ke mortar $\left(\mathrm{mm}^{4}\right)$

Is : Momen inersia kawat jala $\left(\mathrm{mm}^{4}\right)$

\section{HASIL DAN PEMBAHASAN}

Hasil pengujian diameter alir mortar menunjukkan nilai flow pada mortar bekisar 109. Nilai flow ini kemudian dipertahankan konsistansinya untuk setiap pencampuran yang dilakukan agar memiliki kondisi yang sama.

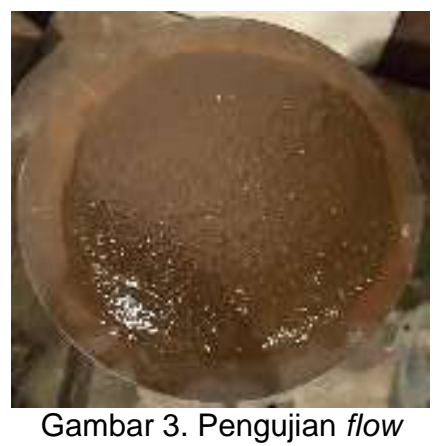

Pengujian kuat tekan pada kajian ini menggunakan benda uji berbentuk kubus dengan ukuran 50x50x50 mm sebanyak tiga buah benda uji yang dilakukan pada umur 1 dan 28 hari. Hasil pengujian dapat dilihat pada Tabel 3.

Tabel 3. Hasil Pengujian Kuat Tekan Mortar

\begin{tabular}{|cccc}
$\begin{array}{c}\text { Kode } \\
\text { Benda Uji }\end{array}$ & Umur & $\begin{array}{c}\text { Hasil } \\
\text { Pengujian } \\
\text { f'c (MPa) }\end{array}$ & $\begin{array}{c}\text { Rata- } \\
\text { Rata } \\
\text { (MPa) }\end{array}$ \\
\hline GM.K1 & 1 & 11,34 & 11,27 \\
\hline GM.K2 & 1 & 11,37 & \\
\hline GM.K3 & 1 & 11,09 & \\
\hline GM.K4 & 28 & 60,67 & 60,84 \\
\hline GM.K5 & 28 & 60,94 & \\
\hline GM.K6 & 28 & 60,91 & \\
\hline
\end{tabular}

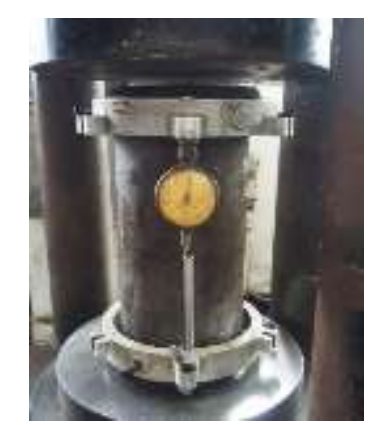

Gambar 4. Pengujian modulus elastisitas

Pada pengujian modulus elastisitas pada kajian ini digunakan benda uji berbentuk silinder dengan diameter $150 \mathrm{~mm}$ dan tinggi $300 \mathrm{~mm}$ sebanyak tiga buah pada umur pengujian 28 hari. Diperoleh nilai modulus elastisitas rata-rata pada 28 hari sebesar $13808 \mathrm{MPa}$. 


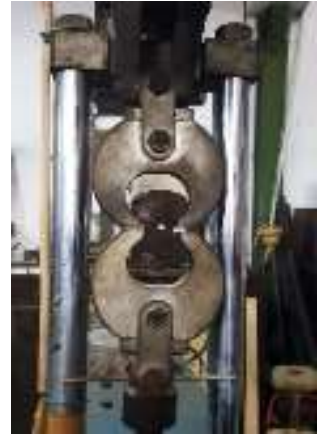

Gambar 5. Pengujian kuat tarik mortar

Pada pengujian kuat tarik pada kajian ini digunakan benda uji berbentuk catbone sebanyak tiga buah benda uji yang dilakukan pada umur 1 dan 28 hari. Hasil pengujian dapat dilihat pada Tabel 4 .

Tabel 4. Hasil Pengujian Kuat Tarik Mortar

\begin{tabular}{cccc}
$\begin{array}{c}\text { Kode } \\
\text { Benda Uji }\end{array}$ & Umur & $\begin{array}{c}\text { Hasil } \\
\text { Pengujian } \\
\text { Kuat Tarik } \\
\text { (MPa) }\end{array}$ & $\begin{array}{c}\text { Rata- } \\
\text { Rata } \\
\text { (MPa) }\end{array}$ \\
\cline { 1 - 2 } GM.T1 & 1 & 1,00 & 1,02 \\
\cline { 1 - 2 } GM.T2 & 1 & 1,05 & \\
\hline GM.T3 & 1 & 1,02 & \multirow{2}{*}{2,95} \\
\hline GM.T4 & 28 & 2,96 & \\
\hline GM.T5 & 28 & 2,85 & \\
\hline GM.T6 & 28 & 3,03 & \\
\hline
\end{tabular}

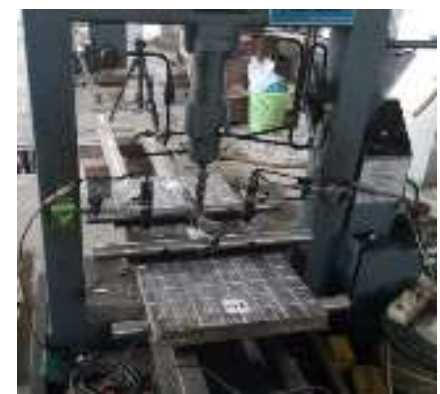

Gambar 6. Pengujian kuat lentur panel

Pada pengujian lentur ini adalah dengan diletakkan benda uji diatas dua tumpuan yang sejajar, kemudian dibebani dengan beban merata yang terletak di tengah bentang, serta dilakukan penambahan beban bertahap hingga menyebabkan benda uji patah untuk mendapatkan nilai beban maksimum (Pmax).

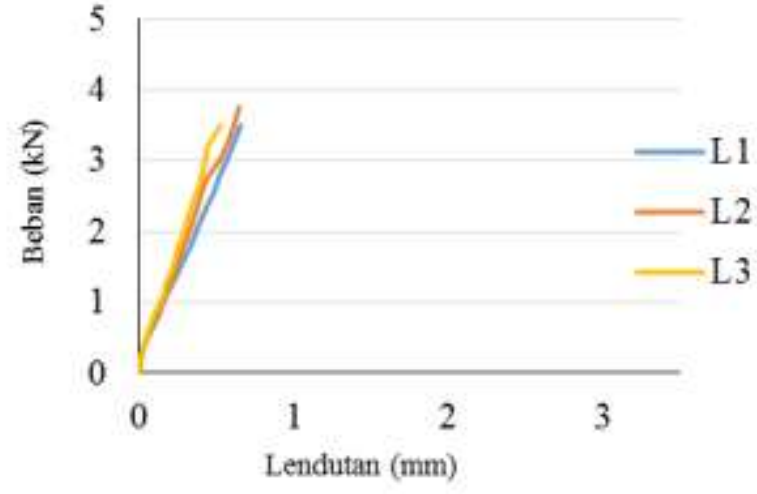

Gambar 7. Grafik hubungan beban dan lendutan benda uji lentur tanpa perkuatan

Hubungan beban dan lendutan benda uji lentur panel dinding tanpa perkuatan ditunjukkan pada Gambar 7. Beban maksimum benda uji L1 yang mampu ditahan panel dinding sebelum mengalami keruntuhan yaitu $3.49 \mathrm{kN}$, benda uji L2 sebesar $3.75 \mathrm{kN}$ dan benda uji L3 sebesar 3.50 kN. Setelah mengalami beban maksimum benda uji mengalami keruntuhan.

Dari hasil pengujian yang telah dilakukan didapatkan pola keruntuhan yaitu terjadi keretakan di daerah terlemah kemudian panel terbelah menjadi dua bagian secara langsung. Pola kerusakan ketiga benda uji mengalami pola keruntuhan yang sama yaitu berada pada tengah bentang. Pola keruntuhan benda uji tanpa perkuatan dapat dilihat pada Gambar 8.

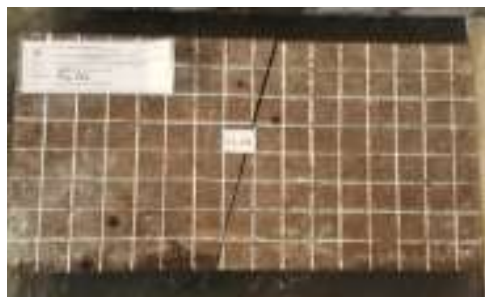

(a)

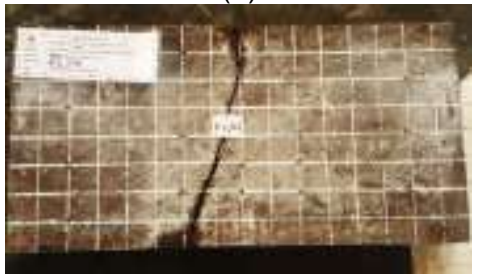

(b) 


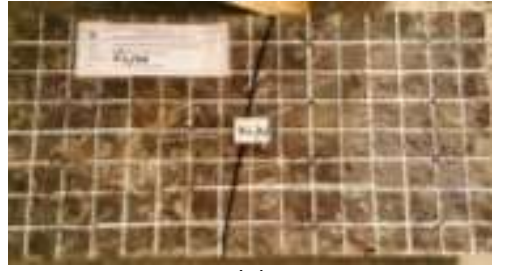

(c)

Gambar 8.(a) Pola kerusakan benda uji L1, (b) Pola kerusakan benda uji L2, (c) Pola kerusakan benda uji L3

Hubungan beban dan lendutan uji lentur panel berbahan geopolimer dapat dilihat pada Gambar 9. Beban maksimum benda uji W1 yang mampu ditahan panel dinding sebelum mengalami keruntuhan yaitu 4,41 $\mathrm{kN}$, benda uji W2 ssebesar 4,66 kN dan benda uji W3 sebesar 4,35 kN.

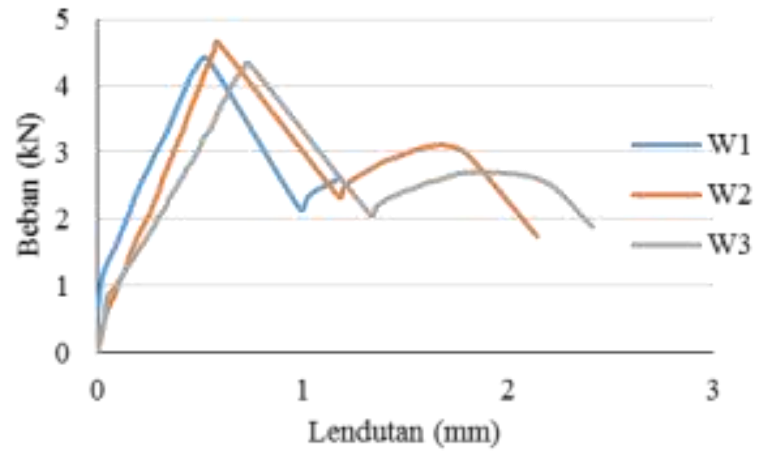

Gambar 9. Grafik hubungan beban dan lendutan benda uji lentur menggunakan perkuatan

Dari grafik dapat diamati bahwa tahap pertama linier, berhenti karena adanya retak pada mortar kemudian beban meningkat terus dan membawa beban tambahan karena adanya perkuatan. Saat perkuatan berupa wiremesh tidak dapat menahan beban maka terjadilah keruntuhan pada panel. Pola kerusakan ketiga benda uji mengalami pola keruntuhan yang sama, pola keruntuhan benda uji dengan perkuatan dapat dilihat pada Gambar 10.

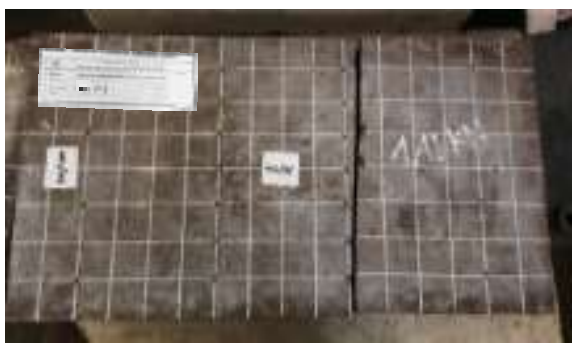

(a)

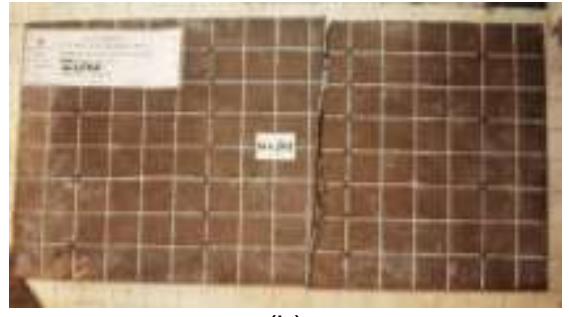

(b)

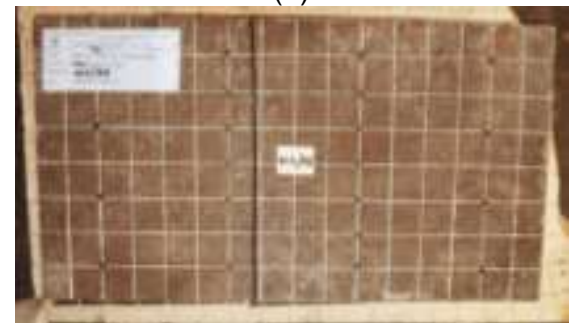

(c)

Gambar 10.(a) Pola kerusakan benda uji W1, (b) Pola kerusakan benda uji W2, (c) Pola kerusakan benda uji W3

Pada Gambar 10. Dapat dilihat pola keruntuhan panel saat pengujian berada tidak tepat di tengah bentang. Hal ini dikarenakan benda uji mengalami kerusakan berupa serat yang terputus di bagian terlemah panel, sehingga menimbulkan retak dan pecah pada bentang tertentu.

Berikut hasil pengujian dinding panel geopolimer pada Tabel 5

Tabel 5. Hasil pengujian tegangan lentur

\begin{tabular}{cccc}
$\begin{array}{c}\text { Kode } \\
\text { Benda } \\
\text { Uji }\end{array}$ & $\begin{array}{c}\text { f'max } \\
\text { (MPa) }\end{array}$ & $\begin{array}{c}\text { Rata- } \\
\text { Rata }\end{array}$ & Ket. \\
\cline { 1 - 2 } L1 & 3,44 & 3,52 & $\begin{array}{c}\text { Non- } \\
\text { Wiremesh }\end{array}$ \\
\cline { 1 - 2 } L2 & 3,68 & & \\
\cline { 1 - 2 } L3 & 3,45 & & Wiremesh \\
\cline { 1 - 2 } W1 & 4,22 & 4,28 & \\
\cline { 1 - 1 } W2 & 4,45 & & \\
\cline { 1 - 1 } W3 & 4,17 & & \\
\hline
\end{tabular}

Berdasarkan hasil pengujian kuat lentur panel didapatkan nilai tegangan lentur dinding panel tanpa menggunakan perkuatan sebesar 3,52 MPa dan dinding panel menggunakan perkuatan sebesar 4,28 MPa. Hasil analisa data yang dilakukan pada pengujian dapat diambil kesimpulan bahwa terjadi peningkatan kuat lentur antara panel tanpa perkuatan terhadap panel menggunakan perkuatan sebesar $21.5 \%$. 


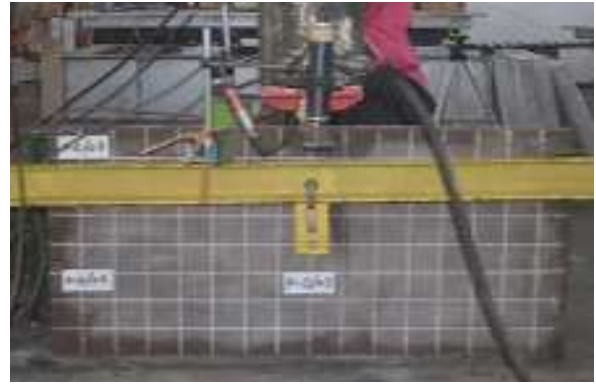

Gambar 11. Pengujian kuat geser panel

Pada kajian ini pengujian geser dilakukan pada umur pengujian selama 28 hari. Perilaku geser pada panel dinding tanpa perkuatan dibandingkan dengan panel dinding dengan menggunakan perkuatan wiremesh masing-masing benda uji untuk pengujian berjumlah 3 buah.
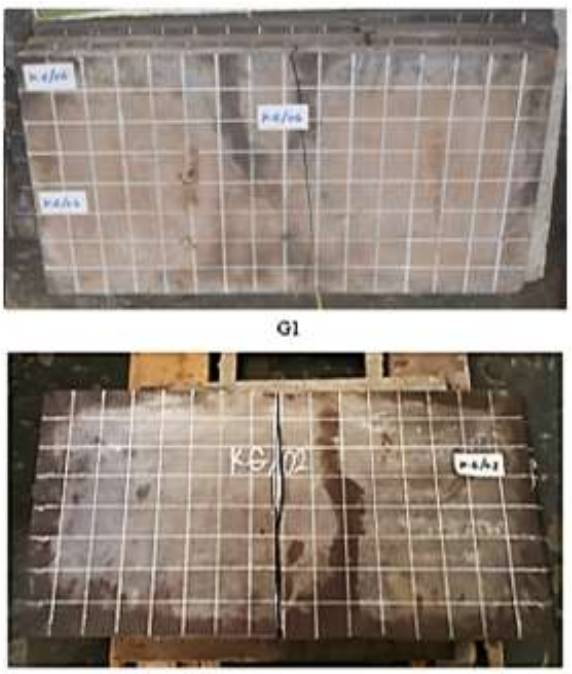

G2

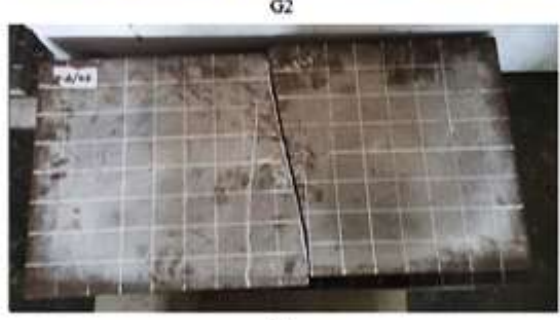

G3

Gambar 12. Pola keruntuhan dinding panel tanpa perkuatan

Dari hasil pengujian yang telah dilakukan didapatkan pola keruntuhan yaitu terjadi keretakan di daerah terlemah pada ketiga panel dinding kemudian panel terbelah menjadi dua bagian secara langsung. Pola kerusakan ketiga benda uji mengalami pola keruntuhan yang sama yaitu berada pada tengah bentang. Ketiga panel dinding bersifat getas, karena setelah mencapai beban maksimum panel dinding langsung mengalami patah.

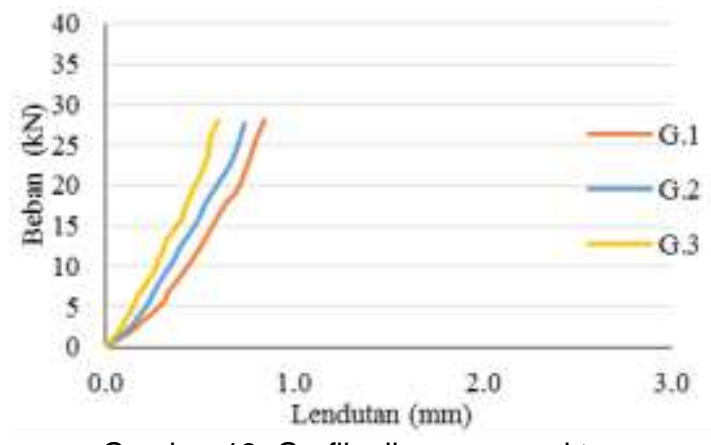

Gambar 13. Grafik uji geser panel tanpa menggunakan perkuatan

Hubungan beban dan lendutan benda uji geser panel dinding tanpa perkuatan ditunjukkan pada Gambar 13. Beban maksimum benda uji $\mathrm{G} 1$ yang mampu ditahan panel dinding sebelum mengalami keruntuhan yaitu $28,1 \mathrm{kN}$, benda uji $\mathrm{G} 2$ sebesar 27,7 kN dan benda uji G3 sebesar $28 \mathrm{kN}$. Dari grafik dapat diamati bahwa tahap pertama linier, berhenti karena adanya retak pada daerah terlemah, pemberian beban diberikan sampai daerah ultimate kemudian terjadilah keruntuhan pada panel.

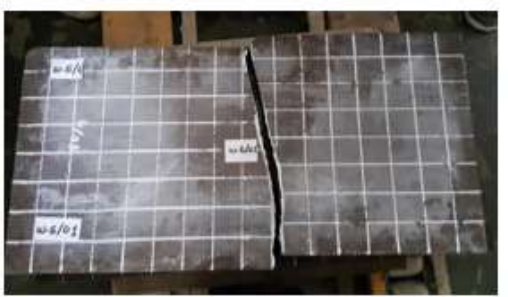

wG.1

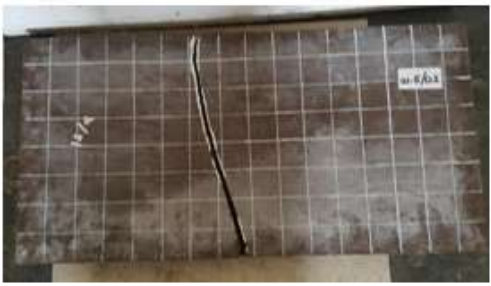

wG. 2

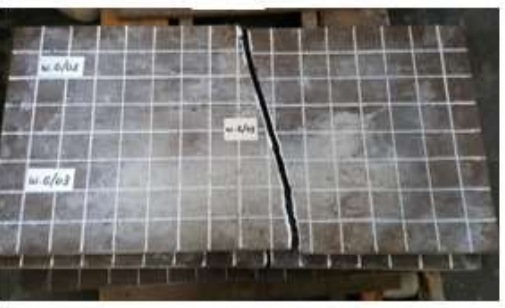

WG.3 
Gambar 14. Pola keruntuhan dinding panel menggunakan perkuatan

Dapat dilihat pola keruntuhan ketiga panel memiliki pola keruntuhan yang sama. Hal ini dikarenakan benda uji mengalami kerusakan berupa serat yang terputus di bagian terlemah panel.

Hubungan beban dan lendutan pada uji geser panel berbahan geopolimer dapat dilihat pada Gambar 15. Beban maksimum benda uji WG. 1 yang mampu ditahan panel dinding sebelum mengalami keruntuhan yaitu $36,1 \mathrm{kN}$, benda uji WG.2 sebesar 36,2 kN dan benda uji WG.3 sebesar $36,1 \mathrm{kN}$.

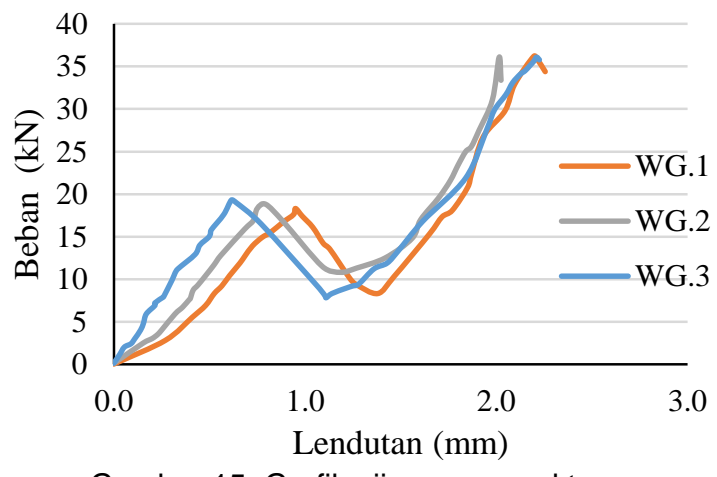

Gambar 15. Grafik uji geser panel tanpa menggunakan perkuatan

Dari grafik dapat diamati bahwa tahap pertama linier, berhenti karena adanya retak dan mengalami penurunan dalam menerima beban kemudian beban kembali naik terus sampai beban maksimal. Hal ini membuktikan wiremesh efektif dalam memberikan kekuatan.

\section{SIMPULAN}

Berdasarkan pengujian sifat-sifat mekanis dinding panel geopolimer dapat diambil kesimpulan sebagai berikut: Hasil pengujian kuat tekan dari material mortar pada umur 1 hari sebesar 11,27 MPa dan pada waktu 28 hari sebesar 60,84 MPa; Dari uji modulus elastisitas dapat kesimpulan bahwa nilai modulus elastisitas pada umur 28 hari sebesar $13808 \mathrm{MPa}$; Kuat tarik geopolimer pada umur 1 hari memperoleh rerata sebesar 1,02 MPa dan 28 hari sebesar 2,95 $\mathrm{MPa}$; Hasil uji kuat lentur pada panel dinding menunjukkan benda uji tanpa perkuatan sebesar 3,52 MPa dan nilai kuat lentur pada panel dengan perkuatan sebesar 4,28 MPa; Hasil analisa data yang dilakukan pada pengujian dapat diambil kesimpulan bahwa terjadi peningkatan kuat lentur antara panel tanpa perkuatan terhadap panel menggunakan perkuatan sebesar $21,5 \%$. Sehingga dapat ditarik kesimpulan bahwa penambahan wiremesh dapat menambah kuat lentur pada panel.

\section{DAFTAR RUJUKAN}

ACI COMMITTEE 549.1R-93. State-of-theArt Report On Ferrocement. ACI 549R93 Code American Concrete Institute.USA.

Aldo, A., \& Pratama, G. N. I. (2019). EVALUASI KETAHANAN GEMPA RUMAH SEDERHANA DI KELURAHAN RUM, KOTA TIDORE KEPULAUAN. INformasi dan Ekspose hasil Riset Teknik Slpil dan Arsitektur, 15(2), 1-9.

ASTM C1437-07. Standard Test Methods of Flow of Hydraulic Cement Mortar.

ASTM C307-03. Standard Test Methods for Tensile Strength of Chemical-Resistant Mortar, Grouts, and Monolithic Surfacings.

ASTM C469-02. Standard Test Methods for Static Modulus of Elaticity and Poisson's Ratio of Concrete in Compression.

ASTM C618-03. ASTM E72-05. Standard Test methods of Conducting Strength Test of panels for Building Construction.

Cornelis, Remigildus. (2018). The Investigation On Setting Time And Strength Of High Calcium Fly Ash Based Geopolymer. 1662-7482, Vol. 881, Pp 158-164.

Duxson P., Fernández-Jiménez A., Provis J. L., Lukey G. C., Palomo A., dan van Deventer J. S. J. (2007) "Geopolymer technology : the current state of the art," J Mater Sci, (4), hal. 2917-2933. doi: 
10.1007/s10853-006-0637-z.

Hardjito. D, dkk. 2002. Enviromentally Driven Geopolymer Cement Applications. Geopolymer Conference. Australia.

Hardjito. D, dkk. 2004. On The Development Of Fly Ash-Based Geopolymer Concrete. ACl Materials Journal, V. 101, No. 6, November-Desember 2004.

Pratama, G. N. I. P., \& Sumarjo, H. (2018). Aksesibilitas Tata Letak Elevator Penumpang Gedung Kantor Pusat Layanan Terpadu (KPLT) Fakultas Teknik UNY. INformasi dan Ekspose hasil Riset Teknik Slpil dan Arsitektur, 14(1), 26-35.

Rajendran, M dan Nagan, S. 2015. Geopolymer Ferrocement Panels Under Flexural Loading. Sci Eng Compos Mater 2015; 22(3): 331-341.

Sari, Dian Maya. 2011. Beton Ringan dari Limbah Styrofoam dengan Perkuatan Wiremesh di Tengah Plesteran. Tesis Universitas Gadjah Mada.

Shah S. P dan Kejin Wang. Development Of "Green" Cement For Sustainable Concrete Using Cement Kiln Dust And Fly Ash. Department of Civil Engineering, Northwestern University, A130 Tech Institute, 2145 Sheridan Road, Evanston, IL 60208, USA.

Singer, L.F., dan Pytel, A. (1985). Kekuatan Bahan (Teori Kokoh-Strength of Materials). Jakarta:Erlangga.

Sreevidya, V, dkk. 2014. Flexural Behavior of Geopolymer Ferrocement Elements. Asian Jurnal of Civil Engineering Vol.15, No.4 (Pages 563-574).

Tjokrodimuljo, Kardiyono. 2012. "Teknologi Beton", Jilid III, Penerbit KMTS FT UGM.
Utomo, Teguh. 2017. Analisa Kuat Tekan Beton Geopolimer Dengan Bahan Alternatif Abu Sekam Padi Dan Kapur Padam. Tugas Akhir Universitas Muhammadiyah Purworejo. 